\title{
Rendimento de cultivares de tomate para processamento em Goias.
}

\author{
Nei Peixoto; José L. de Mendonça²; João Bosco C. da Silva²; Adeliana S. C. Barbedo ${ }^{3}$ \\ ${ }^{1}$ EMATER - GOIÁS - Estação Experimental de Anápolis, C. Postal 608, 75.001-970 Anápolis - GO; ${ }^{2}$ Embrapa Hortaliças, \\ C. Postal 218, 70.359-970 Brasília - DF; ${ }^{3}$ PMSP/SUMA/DEPAVE, av. Paulista, 2073, 01311-940 São Paulo-SP.
}

\section{RESUMO}

Seis ensaios de competição de cultivares de tomate para processamento industrial foram conduzidos nos municípios goianos de Anápolis, Jataí, Porangatú e Santa Isabel, em 1990, e Anápolis e Porangatu, em 1991. O delineamento experimental utilizado foi de blocos casualizados com quatro repetições, tendo as parcelas 80 plantas em 1990 e 70 em 1991. Em Porangatu, em 1990, as plantas foram mais precoces, florescendo 35 e 41 dias após a semeadura e iniciando-se a colheita 38 dias após a antese. Em Anápolis, também em 1990, a floração iniciou-se de 54 a 60 dias após a semeadura e, a colheita, 46 dias após a antese. As cultivares Petomech, IPA 6 e Topmech Melhorado destacaram-se entre as mais produtivas, apresentando frutos firmes, seguidas das cultivares IPA 5 e Agrocica 72. As cultivares Roma VFN, Rossol e Agrocica 08, por outro lado, revelaram-se produtivas, mas com frutos pouco firmes, sendo impróprias para o transporte a longa distância. Com exceção da cultivar Itaparica, que apresentou melhor desempenho relativo nos ambientes menos favoráveis, os genótipos apresentaram, para rendimento, resposta diretamente proporcional à melhoria do ambiente, caracterizado pela média geral dos genótipos dentro de cada experimento. As cultivares Agrocica 08, IPA 5, Nemadoro e UC 204, foram as mais influenciadas pelas variações do ambiente, enquanto as cultivares Agrocica 33, Calmec VF, IPA 6, Rio Fuego, Santa Adélia, Topmec Melhorado e UC 82 foram as mais estáveis.

Palavras-chave: Lycopersicon esculentum, melhoramento, rendimento, adaptabilidade, estabilidade, interacao genotipo x ambiente.

\section{ABSTRACT}

Yield of processing tomato cultivars in Goiás State, Brazil.

Six field trials were carried out to evaluate processing tomato cultivars in four counties in the State of Goiás, Brazil (Anápolis, Jataí, Porangatú and Santa Isabel, in 1990, and Anápolis and Porangatu, in 1991). The experiment was conducted as a randomized block design, with four replications, and plots of 80 plants in 1990 and 70 plants in 1991. The plant cycle was shorter in Porangatu (1990), where temperatures were higher than Anápolis. In Porangatu, plant flowering began 35 to 41 days after sowing, with the harvesting period starting 38 days later. Cultivars Petomech, IPA 6, and Improved Topmech, followed by IPA 5 and Agrocica 72, were high yielding and showed a high fruit firmness. Cultivars Roma VFN, Rossol and Agrocica 08, were also high yielding but produced fruits unsuitable for long distance transportation. With the exception of cultivar Itaparica, which showed the best adaptation to less favourable enviroments, all genotypes were responsive to enviroment improvement. Higher stability to environmental variation was observed in cultivars Agrocica 33, Calmec VF, IPA 6, Rio Fuego, Santa Adélia, Topmec Melhorado, and UC 82.

Keywords: Lycopersicon esculentum, breeding, yield, adaptability, stability, genotype $x$ environment interaction.

\section{(Aceito para publicação em 23 de outubro de 1998)}

$\mathrm{O}$ primeiros plantios comerciais de tomate para processamento industrial em Goiás ocorreram em Morrinhos, em 1974, utilizando-se a cultivar Roma VF, cuja produção destinava-se às indústrias paulistas (Filgueira et al., 1976). Em 1975, a Escola de Agronomia da Universidade Federal de Goiás e a Empresa Goiana de Pesquisa Agropecuária - EMGOPA - conduziram os primeiros ensaios de introdução e avaliação de cultivares de tomate para processamento em Goiás, respectivamente em Goiânia (Sonnenberg et al., 1976) e Anápolis (Filgueira et al., 1976; 1978). A expansão das lavouras ocorreu em conseqüência da implantação de indústrias de processamento em Goiás e em função das condições favoráveis de clima e solo do sul do estado.

Desde então, muitas cultivares de tomate para processamento industrial têm sido avaliadas. Entretanto, este é um trabalho que nao chegou ao fim, já que o problema principal das indústrias de processamento, referente à sazonalidade e coincidência de colheitas em todas as regiões brasileiras, ainda não foi resolvido. Essa concentração da safra exige grande infra-estrutura para armazenamento de polpa semi-processada (Pereira \& Rauen, 1989) e tem levado as empresas a importar pasta de tomate de 30-32 ${ }^{\circ}$ Brix, passando a manter menor estoque de passagem (Melo, 1993). A importação de polpa concentrada, principalmente do Chile e da Argentina, acarretou retração das áreas cultivadas e, em determinados anos, a falta de matéria prima, em função da escassez temporária do produto no mercado internacional. Obviamente, a solução dessa questão não reside exclusivamente em encontrar cultivares mais adequadas. Entretanto, a identificação de cultivares melhor adaptadas ao plantio em épocas que escapem ao período de safra ou a regiões onde essa estratégia seja possivel é uma parte importante dessa solução.

A avaliação de novas cultivares tem ainda a finalidade de estudar os genótipos, nacionais e estrangeiros, que têm sido constantemente introduzidos no mercado brasileiro de sementes. Assim, espera-se poder realizar melhor o trabalho de recomendação de cultivares produtivas, buscando preferencialmente, aquelas com maior resistência a doenças e que apresentem boa qualidade para processamento.

Para uma recomendação eficiente de cultivares é preciso ainda realizar ensaios repetidos no tempo e no espaço, que permitam avaliar a estabilidade das cultivares na expressão fenotípica de de- 
terminadas caracteristicas. Sabe-se que as diferenças gênicas e ambientais contribuem independentemente umas das outras para a variação do fenótipo (Mather \& Jinks, 1984). Assim o estudo da interação genótipos $\mathrm{x}$ ambientes torna-se imprescindível, tanto em programas de melhoramento, na escolha de progenitores, como na indicação e liberação de cultivares (Finlay \& Wilkinson, 1963: Eberhart \& Russel, 1966; Banzatto, 1994; Cruz \& Regazzi, 1994). Uma cultivar desejável deve apresentar alto rendimento médio, resposta positiva à melhoria do ambiente $\left(\mathrm{b}_{\mathrm{ij}} @ 1\right) \mathrm{e}$ comportamento previsível $\left(\operatorname{sd}_{\mathrm{ij}} @ 0\right)$

O presente trabalho teve como objetivo avaliar cultivares de tomate para processamento em diferentes condições edafoclimáticas do estado de Goiás.

\section{MATERIAL E MÉTODOS}

Conduziram-se, em 1990 e 1991, em solos de cerrado, seis experimentos de competição de cultivares de tomate para processamento em Goiás, nos municípios de Anápolis, Jataí, Porangatú e Santa Isabel, como parte dos Ensaios Nacionais de Cultivares de Tomate, coordenados pela Embrapa Hortaliças. O delineamento experimental utilizado foi blocos casualizados, com quatro repetições, tendo as parcelas 80 plantas em $1990 \mathrm{e}$ 70 em 1991, dispostas em fileiras duplas, no espaçamento de $1,30 \times 0,50 \times 0,20 \mathrm{~m}$. As semeaduras ocorreram em 17 de maio de 1990 e 16 de maio de 1991, em Anápolis; em 7 de junho de 1990, em Jataí; em 25 de maio de 1990 e 30 de abril de 1991, em Porangatú e; em 15 de maio de 1990 em Santa Isabel.

A adubação de plantio variou para cada experimento. Em 1990, os níveis adotados, em kg/ha de $\mathrm{N}, \mathrm{P}_{2} \mathrm{O}_{5}$ e $\mathrm{K}_{2} \mathrm{O}$, foram 80, 320 e 160, em Anápolis; 40, 350 e 100, em Jataí e Porangatú e; 40, 390 e 96 em Santa Isabel. Em 1991 as quantidades utilizadas desses mesmos fertilizantes, em kg/ha, foram, respectivamente, 40, 300 e 120 em Anápolis e 60,450 e 240 em Porangatú, acrescentando-se, em Anápolis, $600 \mathrm{~kg} / \mathrm{ha}$ de Yoorin BZ e, em Porangatú, $100 \mathrm{~kg} / \mathrm{ha}$ de FTE BR-12. As adubações em cobertura também variaram, sendo sempre divididas em duas aplicações iguais,
20 e 35 dias após a semeadura. Foram utilizados, por hectare, $120 \mathrm{~kg}$ de $\mathrm{N} \mathrm{e}$ $40 \mathrm{~kg}$ de $\mathrm{K}_{2} \mathrm{O}$, em Anápolis, nos dois anos; $80 \mathrm{~kg}$ de N, em Jataí e Porangatú, em 1990; $104 \mathrm{~kg}$ de N, $60 \mathrm{~kg}$ de $\mathrm{P}_{2} \mathrm{O}_{5} \mathrm{e}$ $96 \mathrm{~kg}$ de $\mathrm{K}_{2} \mathrm{O}$, em Santa Isabel, em 1990 e, finalmente, $150 \mathrm{~kg}$ de $\mathrm{N}$ e $44 \mathrm{~kg}$ de $\mathrm{K}_{2} \mathrm{O}$, em Porangatú, em 1991.

Foram avaliadas as cultivares Agrocica 08, Agrocica 33, Agrocica 72, Calmec Gigante, Calmec VF, IPA 5, IPA 6, Itaparica, Nemadoro, Petomech, Rio Fuego, Rio Grande, Roma VFN, Rossol, Santa Adélia, Topmech Melhorado, UC 82 e UC 204. Os experimentos receberam os tratos culturais normalmente recomendados para as lavouras de tomate para processamento e foram irrigados por aspersão convencional, exceto em Santa Isabel e Jataí, onde foram conduzidos sob pivô-central.

Foram obtidos os dados de produção em número e peso de frutos maduros por parcela e convertidos em t/ha e peso médio, realizando-se de uma a três colheitas. Os dados de cada experimento foram submetidos à análise estatística, fazendo-se análises de variância individuais e conjunta e o estudo de interação genótipos $\mathrm{x}$ ambientes, segundo o método de Eberhart \& Russell (1966), utilizando-se os recursos computacionais do programa IGA, desenvolvido pela equipe de estatísticos da Universidade Estadual Paulista, Campus de Jaboticabal. A metodologia de Eberhart \& Russell baseia-se nos procedimentos de análise por regressão, que estabelece um índice ambiental para cada experimento, baseado na média da produtividade dos genótipos no experimento. Para cada genótipo é feita uma análise de regressão, utilizando-se o índice ambiental como variável independente e a produção desse genótipo como variável dependente. Assim, o efeito do ambiente pode ser desmembrado em dois componentes, um linear e outro não linear. O coeficiente de regressão (b) está associado ao componente linear, que indica a adaptabilidade do genótipo, ou seja, sua capacidade de responder à melhoria do ambiente. $\mathrm{O}$ desvio da regressão ( $\mathrm{s}^{2} \mathrm{~d}$ ) está associado ao componente não linear e indica a estabilidade de comportamento do genótipo. As médias foram comparadas pelo teste de Tukey, a 5\% de probabilidade.

\section{RESULTADOS E DISCUSSÃO}

Foram observadas, em 1990, diferenças no ciclo vegetativo entre os experimentos conduzidos em Anápolis e Porangatú, provavelmente em função das diferenças climáticas. Em Porangatú, sob temperaturas mais elevadas, as plantas foram mais precoces, florescendo entre 35 e 41 dias após a semeadura e alcançando maturação de $50 \%$ dos frutos 73 a 79 dias também após a semeadura. Em Anápolis a floração ocorreu entre 54 e 60 dias e, a maturação, entre 100 e 111 dias após a semeadura. Em todos os experimentos o desenvolvimento da cor dos frutos foi normal.

Os rendimentos obtidos foram relativamente baixos em todos os experimentos (Tabela 1), especialmente se comparados ao rendimento máximo de 88,9 t/ha (Saturnino et al., 1993) obtido em Minas Gerais, ou ainda ao rendimento de 90,1 t/ha obtido por Marouelli \& Silva (1993), em Brasília. Entretanto, os rendimentos aqui relatados se assemelham àqueles obtidos por Braz et al. (1991), em Jaboticabal (SP), onde a produtividade variou entre 14,07 e 46,52 t/ha.

Entre as cultivares de produtividade mais elevada, destacaram-se, por apresentar maior firmeza de fruto, as cultivares Petomech, IPA 6 e Topmech Melhorado, seguidas de IPA 5 e Agrocica 72 , resultados consonantes com os encontrados por Melo (1989). As cultivares Roma VFN e Rossol mostraram-se produtivas nos diferentes ensaios em que foram incluídas em Goiás, inclusive aqueles conduzidos por Sonnenberg et al. (1976) e Filgueira et al. (1976). Entretanto, essas cultivares apresentam frutos de pouca firmeza, não sendo recomendadas para transporte a longa distância. Neste grupo também se enquadra a cultivar Agrocica 08, que se mostrou produtiva, exceto em Jataí, em 1990 (Tabela 1). O peso médio dos frutos nos diferentes experimentos variou de 30 a $90 \mathrm{~g}$, com destaque especial para as cultivares Petomech e IPA 6 que, além de produtivas, apresentaram frutos com aptidão para o consumo ao natural como alternativa às cultivares do grupo Santa Cruz. Os rendimentos médios dos genótipos nos experimentos localizados em 
Tabela 1. Rendimento (t/ha) de frutos maduros de cultivares de tomate para processamento em Anápolis, Jataí, Porangatú e Santa Isabel, 1990 e 1991. Anapolis, EMATER - GO, 1998.

\begin{tabular}{lllllllll}
\hline \multirow{2}{*}{ Cultivares } & \multicolumn{9}{c}{1990} & \multicolumn{2}{c}{ 1991 } & Média \\
\cline { 2 - 6 } & Anápolis & \multicolumn{1}{c}{ Jataí } & Porangatú & Santa Isabel & Anápolis & Porangatú & (seis locais) \\
\hline Agrocica 08 & $45,72 \mathrm{a}$ & $20,38 \mathrm{~b}$ & $32,60 \mathrm{a}$ & $31,03 \mathrm{ab}$ & $37,83 \mathrm{abc}$ & $36,65 \mathrm{ab}$ & $34,03 \mathrm{ab}$ \\
Agrocica 33 & $35,42 \mathrm{abc}$ & $32,21 \mathrm{ab}$ & $18,90 \mathrm{ab}$ & $28,91 \mathrm{ab}$ & $36,55 \mathrm{abc}$ & $40,51 \mathrm{ab}$ & $32,08 \mathrm{ab}$ \\
Agrocica 72 & $35,48 \mathrm{abc}$ & $19,20 \mathrm{~b}$ & $30,56 \mathrm{a}$ & $26,86 \mathrm{ab}$ & $45,24 \mathrm{ab}$ & $42,68 \mathrm{ab}$ & $33,34 \mathrm{ab}$ \\
Calmec Gigante & $25,75 \mathrm{c}$ & $15,90 \mathrm{~b}$ & $13,07 \mathrm{~b}$ & $31,67 \mathrm{ab}$ & $35,05 \mathrm{abc}$ & $38,18 \mathrm{ab}$ & $26,60 \mathrm{~b}$ \\
Calmec VF & $41,76 \mathrm{abc}$ & $28,22 \mathrm{ab}$ & $22,88 \mathrm{ab}$ & $24,19 \mathrm{~b}$ & $40,02 \mathrm{abc}$ & $40,63 \mathrm{ab}$ & $32,95 \mathrm{ab}$ \\
IPA 5 & $34,90 \mathrm{abc}$ & $22,14 \mathrm{ab}$ & $34,57 \mathrm{a}$ & $29,05 \mathrm{ab}$ & $36,09 \mathrm{abc}$ & $51,09 \mathrm{a}$ & $34,64 \mathrm{ab}$ \\
IPA 6 & $41,68 \mathrm{abc}$ & $28,63 \mathrm{ab}$ & $27,81 \mathrm{ab}$ & $37,83 \mathrm{a}$ & $38,06 \mathrm{abc}$ & $41,60 \mathrm{ab}$ & $35,93 \mathrm{ab}$ \\
Itaparica & $26,76 \mathrm{bc}$ & $30,26 \mathrm{ab}$ & $31,55 \mathrm{a}$ & $27,62 \mathrm{ab}$ & $23,86 \mathrm{c}$ & $31,72 \mathrm{~b}$ & $28,63 \mathrm{ab}$ \\
Nemadoro & $30,08 \mathrm{bc}$ & $31,23 \mathrm{ab}$ & $13,45 \mathrm{~b}$ & $25,83 \mathrm{ab}$ & $28,10 \mathrm{bc}$ & $36,95 \mathrm{ab}$ & $27,61 \mathrm{~b}$ \\
Petomech & $50,09 \mathrm{a}$ & $28,11 \mathrm{ab}$ & $24,73 \mathrm{ab}$ & $32,22 \mathrm{ab}$ & $38,44 \mathrm{abc}$ & $42,67 \mathrm{ab}$ & $36,04 \mathrm{ab}$ \\
Rio Fuego & $26,17 \mathrm{bc}$ & $26,12 \mathrm{ab}$ & $22,09 \mathrm{ab}$ & $23,56 \mathrm{~b}$ & $33,68 \mathrm{abc}$ & $40,31 \mathrm{ab}$ & $28,65 \mathrm{ab}$ \\
Rio Grande & $37,58 \mathrm{abc}$ & $29,61 \mathrm{ab}$ & $14,24 \mathrm{~b}$ & $29,31 \mathrm{ab}$ & $28,98 \mathrm{bc}$ & $40,58 \mathrm{ab}$ & $30,05 \mathrm{ab}$ \\
Roma VFN & $40,75 \mathrm{abc}$ & $41,12 \mathrm{a}$ & $30,68 \mathrm{a}$ & $31,81 \mathrm{ab}$ & $50,46 \mathrm{a}$ & $40,14 \mathrm{ab}$ & $39,16 \mathrm{a}$ \\
Rossol & $45,81 \mathrm{ab}$ & $35,77 \mathrm{ab}$ & $24,87 \mathrm{ab}$ & $27,11 \mathrm{ab}$ & $43,93 \mathrm{abc}$ & $35,56 \mathrm{ab}$ & $35,51 \mathrm{ab}$ \\
Sta. Adélia & $36,67 \mathrm{abc}$ & $24,00 \mathrm{ab}$ & $23,46 \mathrm{ab}$ & $34,44 \mathrm{ab}$ & $38,41 \mathrm{abc}$ & $35,54 \mathrm{ab}$ & $32,09 \mathrm{ab}$ \\
Topmech Melh. & $27,18 \mathrm{bc}$ & $27,18 \mathrm{ab}$ & $25,47 \mathrm{ab}$ & $26,25 \mathrm{ab}$ & $40,63 \mathrm{a}$ & $43,90 \mathrm{ab}$ & $32,18 \mathrm{ab}$ \\
UC-82 & $35,09 \mathrm{ab}$ & $24,74 \mathrm{ab}$ & $20,67 \mathrm{ab}$ & $22,78 \mathrm{~b}$ & $45,10 \mathrm{ab}$ & $33,90 \mathrm{ab}$ & $30,38 \mathrm{ab}$ \\
UC-204 & $22,91 \mathrm{c}$ & $25,32 \mathrm{ab}$ & $21,41 \mathrm{ab}$ & $28,75 \mathrm{ab}$ & $39,15 \mathrm{abc}$ & $41,11 \mathrm{ab}$ & $29,77 \mathrm{ab}$ \\
\hline CV (\%) & 21,37 & 28,43 & 25,86 & 17,14 & 21,35 & 16,78 & - \\
\hline
\end{tabular}

Tukey $5 \%$

Tabela 2. Análise de adaptabilidade e estabilidade de 18 genótipos de tomate para processamento, em seis ambientes, de acordo com o método de Eberhart \& Russell (1966). Anápolis, EMATER - GO, 1998

\begin{tabular}{|c|c|c|c|c|c|}
\hline \multirow{2}{*}{ Genótipo } & \multirow{2}{*}{$\begin{array}{c}\text { Produção média } \\
\text { (t/ha) } \\
\alpha_{\mathrm{i}} \\
\end{array}$} & \multicolumn{2}{|c|}{ Coeficiente de regressão } & \multirow{2}{*}{$\begin{array}{c}\text { Desvios de } \\
\text { regressão } \\
\sigma^{2} \delta_{i j} \\
\end{array}$} & \multirow{2}{*}{$\begin{array}{l}\text { Coeficiente de } \\
\text { determinação } \\
\mathbf{R}_{\mathrm{i}}^{2}\end{array}$} \\
\hline & & $\beta_{i}$ & $\mathbf{t}\left(\boldsymbol{\beta}_{\mathrm{i}}\right)$ & & \\
\hline Agrocica 08 & 34,0325 & 0,8431 & $-0,31 \mathrm{~ns}$ & $40,9447 * *$ & $0,4028 \mathrm{~ns}$ \\
\hline Agrocica 33 & 32,0817 & 1,0768 & $0,30 \mathrm{~ns}$ & $1,0610 \mathrm{~ns}$ & $0,8160^{*}$ \\
\hline Agrocica 72 & 33,3375 & 1,2868 & $0,67 \mathrm{~ns}$ & $25,3253^{*}$ & $0,6901 *$ \\
\hline Calmec Gigante & 26,6021 & 1,3798 & $0,89 \mathrm{~ns}$ & $24,3773^{*}$ & $0,7243^{*}$ \\
\hline Calmec VF & 32,9479 & 1,3004 & $1,25 \mathrm{~ns}$ & - 0,4293ns & $0,8794 * *$ \\
\hline IPA 5 & 34,6383 & 1,0586 & $0,11 \mathrm{~ns}$ & $46,5665 * *$ & $0,49.02 \mathrm{~ns}$ \\
\hline IPA 6 & 35,9325 & 0,8425 & $-0,63 n s$ & $0,3147 \mathrm{~ns}$ & $0,7421^{*}$ \\
\hline Itaparica & 28,6228 & $-0,1933$ & $-5,33 * *$ & $-1,9945 \mathrm{~ns}$ & $0,1569 \mathrm{~ns}$ \\
\hline Nemadoro & 27,6067 & 0,9135 & $-0,21 \mathrm{~ns}$ & $23,5022 * *$ & $0,5413 \mathrm{~ns}$ \\
\hline Petomech & 36,0433 & 1,2632 & $0,65 \mathrm{~ns}$ & $20,6966^{*}$ & $0,7101^{*}$ \\
\hline Rio Fuego & 28,6529 & 0,9450 & $-0,20 \mathrm{~ns}$ & $3,6465 \mathrm{~ns}$ & $0,7406^{*}$ \\
\hline Rio Grande & 30,0492 & 1,1471 & $0,34 \mathrm{~ns}$ & $26,5187 *$ & $0,6317 \mathrm{~ns}$ \\
\hline Roma VFN & 39,1575 & 0,7992 & $-0,50 \mathrm{~ns}$ & $21,0178 *$ & $0,4926 \mathrm{~ns}$ \\
\hline Rossol & 35,5058 & 0,9749 & $-0,05 n s$ & $30,2982^{*}$ & $0,5302 \mathrm{~ns}$ \\
\hline Santa Adélia & 32,0863 & 0,8919 & $-0,40 \mathrm{~ns}$ & $2,4220 \mathrm{~ns}$ & $0,7338^{*}$ \\
\hline Topmec Melhorado & 32,1754 & 1,1521 & $0,40 \mathrm{~ns}$ & $17,6398 \mathrm{~ns}$ & $0,6920 *$ \\
\hline UC 82 & 30,3775 & 1,2830 & $0,79 \mathrm{~ns}$ & $13,8138 \mathrm{~ns}$ & $0,7618^{*}$ \\
\hline UC 204 & 29,7729 & 1,0355 & $0,09 \mathrm{~ns}$ & $22,5103 * *$ & $0,6093 \mathrm{~ns}$ \\
\hline
\end{tabular}


Anápolis, 1990 e 1991, e em Porangatu, 1991, foram estatisticamente superiores àqueles obtidos em Santa Isabel, Jataí e Porangatú, em 1990 (Tabela 1).

As cultivares Agrocica 08, IPA 5, Nemadoro e UC 204, foram as mais influenciadas pelas variações do ambiente, enquanto as cultivares Agrocica 33, Calmec VF, IPA 6, Rio Fuego, Santa Adélia, Topmec Melhorado e UC 82 foram as mais estáveis. Com exceção da cultivar Itaparica, que apresentou melhor desempenho relativo nos ambientes menos favoráveis, os genótipos apresentaram resposta proporcional à melhoria do ambiente, caracterizado pelo rendimento médio dentro de cada local (Tabela 2).

\section{AGRADECIMENTOS}

Os autores agradecem ao apoio dos técnicos agrícolas Antônio de Pádua Pereira, Brasiliano Correia Filho e Francisco da Mota Moreira, pelo acompanhamento dos ensaios, e aos senhores Justiniano Dias Diniz e Caio Junqueira por terem viabilizado os ensaios localizados em suas propriedades, nos municípios de Santa Isabel e Jataí, respectivamente.

\section{LITERATURA CITADA}

BANZATTO, D.A. Comparação de métodos de avaliação da adaptabilidade e estabilidade de cultivares de batata. Jaboticabal: Universidade Estadual Paulista - Faculdade de Ciências Agrárias e Veterinárias, 1994. 170 p. (Tese livre docência)

BRAZ, L.T.; CARVALHO, J.B.; CHURATA-MASCA, M.G.C. Evaluation of the performance of some processing tomato varieties in the region of Jaboticabal, São Paulo, Brazil. In: INTERNATIONAL SYMPOSIUM ON TOMATOES FOR INDUSTRY, 1991, Mendoza, Argentina. (Abstracts...) Mendoza: ISHS, 1991. não paginado.

CRUZ, C.D.; REGAZZI, A.J. Modelos biométricos aplicados ao melhoramento de plantas. Viçosa: Imprensa Universitária, 1994. 330 p.

EBERHART, S.A.; RUSSELL, W.A. Stability parameters for comparing varieties. Crop Science, v. 6, p. 36-40, 1966.

FILGUEIRA, F.A.R.; SONNENBERG, P.E.; OGATA, T. Competição entre cultivares de tomate industrializável (Lycopersicon esculentum) de crescimento determinado no período chuvoso em Anápolis. Revista de Olericultura, v. 16, p. 184-187, 1976.

FILGUEIRA, F.A.R.; SONNENBERG, P.E.; OGATA, T. Avaliação de características agronômicas e industriais de cultivares de tomate, introduzidas em Anápolis, em cultura rasteira. Goiânia: EMGOPA - DDI, 1978. 17 p. (Comunicado técnico 08).
FINLAY, K.W.; WILKINSON, G.N. The analysis of adaptation in a plant breeding program. Australian Journal of Agricultural Research, v. 14, n. 6 , p. $742-754,1963$.

MAROUELLI, W.A.; SILVA, W.L.C. Adequação da época de paralização das irrigações em tomate industrial no Brasil Central. Horticultura Brasileira, Brasilia, v. 11, n. 2, p. 118-121, 1993.

MATHER, K.; JINKS, J.L. Introdução à genética biométrica. Ribeirão Preto: Sociedade Brasileira de Genética, 1984. 242 p.

MELO, P.C.T. de. Melhoramento genético do tomateiro. Campinas: ASGROW, 1989. 55 p.

MELO, P.C.T. de. Retrospectiva da indústria de tomate no Brasil nos anos 90. Horticultura Brasileira, Brasilia, v. 11, n. 2, p. 109-111, 1993.

PEREIRA, E.C.M.; RAUEN, A.J. Tomate industrial, exigências industriais, custo de produção e preço mínimo. In: ENCONTRO NACIONAL DE PRODUÇÃO E ABASTECIMENTO DE TOMATE, 1., 1989, Viçosa. (Anais...). Vicosa: Imprensa Universitaria, 1989. p. 18-26.

SATURNINO, H.M.; SILVA, J.B.C. da; ROCHA, S.L.; SILVA, R.A.; GONÇALVES, P.G. Ensaio nacional de tomate industrial em Minas Gerais. In: EPAMIG. Relatório de Pesquisa. Belo Horizonte: EPAMIG, 1993. p. 286290 (Projeto Olericultura 87/92)

SONNENBERG, P.E.; FILGUEIRA, F.A.R.; MARTINS, J.C. Competição entre cultivares de tomate industrializável (Lycopersicon esculentum) de crescimento determinado no período seco em Goiânia. Revista de Olericultura, v. 16, p. 188-190, 1976.

RESENDE, G.M. de. Produção de cultivares de pepino para conserva na região Norte de Minas Gerais. Horticultura Brasileira, Brasília, v. 17, n. 1, p. 57-60, março 1999. 